\title{
Actuating Sebagai Penyokong Produktivitas Kerja PT. PLN (Persero) Pembangkitan Sumatera Bagian Utara Sektor Pembangkitan Pandan
}

\author{
Yenni Sofiana Tambunan ${ }^{1}$ \\ Sekolah Tinggi Ilmu Ekonomi Al-Washliyah Sibolga \\ yennisofiana@gmail.com
}

\begin{abstract}
Abstrak
Analisis yang dilakukan yaitu untuk mencari tahu pengaruh Actuating terhadap Produktivitas Kerja pada PT.PLN (Persero) Pembangkitan Sumatera Bagian Utara Sektor Pembangkitan Pandan, sedangkan hipotesis yang diperoleh bahwa Actuating berpengaruh terhadap Produktivitas Kerja pada PT.PLN (Persero) Pembangkitan Sumatera Bagian Utara Sektor Pembangkitan Pandan. Populasi 45 orang dan sekaligus dijadikan sampel. Metode analisis yang digunakan yaitu Uji Koefisien Korelasi, Uji Determinasi, Regresi Linier Sederhana dan Uji t-statistik. Hasil Teknik analisis data yang diperoleh bahwa hubungan kuat Actuating terhadap Produktivitas Kerjan dengan koefisien korelasi diperoleh 0,683. Hasil koefisien determinasi sebesar 46,65\% memberi arti bahwa Produktivitas Kerja dapat dipengaruhi oleh Actuating sebesar 46,56\% dan sisanya sebesar $53,35 \%$ dipengaruhi oleh faktor lain yang tidak dibahas dalam penelitian ini. Berdasarkan regresi linear sederhana diperoleh model persamaan $\mathrm{Y}=14,036+0,664 \mathrm{X}$ menunjukkan kearah positif. Nilai t-hitung lebih besar dari pada t-tabel yaitu 6,138>2.0167, sehingga dapat disimpulkan hipotesis yang diajukan dapat diterima.
\end{abstract}

Kata kunci: Actuating, Produktivitas Kerja

\section{Pendahuluan}

Dalam sebuah organisasi sudah sepatutnya terdapat pelaksanaan setelah suatu perencanaan dan pembentukan organisasi. Dalam pelaksanaan dibutuhkan prinsip, teknik dan tahapan yang optimal. Pelaksanaan atau bisa disebut penggerakan (actuating) yaitu menggerakkan semua personal agar mau bekerjasama dan bekerja efektif dalam mencapai tujuan suatu organisasi. terdapat banyak prinsip dalam penggerakan yang harus dibahas dalam penelitian ini, selain prinsip penggerakan juga banyak teknik dalam penggerakann dan lebih menekankan pada kegiatan yang berhubungan langsung dengan orang-orang dalam organisasi.

Keberadaan sumber daya manusia yang berada dalam sebuah perusahaan tidak akan berjalan dengan baik apabila tenaga kerjanya tidak mampu diarahkan dan digerakkan dengan benar karena jika tidak perkembangan perusahaan tidak stabil, dan produktivitas karyawan menjadi menurun, oleh karena itu actuating sangat penting agar produktivitas kerja karyawan menjadi efektif.

Actuating merupakan usaha menggerakkan anggota-anggota kelompok sedemikian rupa hingga mereka berkeinginan dan berusaha untuk mencapai sasaran perusahaan dan sasaran anggotaanggota perusahaan tersebut oleh karena para anggota itu juga ingin mencapai sasaran-sasaran tersebut.

Produktivitas kerja karyawan bagi perusahaan sangatlah penting sebagai alat pengukur keberhasilan dalam perusahaan, karena semakin tinggi produktivitas kerja karyawan dalam perusahaan, berarti laba perusahaan dan produkktivitas akan meningkat. Pentingnya produktivitas

${ }^{1}$ Korespondensi: Yenni Sofiana Tambunan. Sekolah Tinggi Ilmu Ekonomi Al- Washliyah Sibolga, Jl. Sibolga KM. 5 Sarudik Sibolga, Tapanuli Tengah. yennisofiana@gmail.com 
agar dapat meningkatkan kinerja yang baik, selain itu juga merupakan balas jasa yang diberikan perusahaan agar dapat mempertahankan pegawai dalam perusahaan.

Masih banyak perusahaan yang belum maksimal peningkatan produktivitas kerja karyawan, sehingga memicu karyawan bekerja dengan asal-asalan, malas, dan tidak sungguh-sungguh. Maka perusahaan perlu membuat program kesejahteraan yang adil da bijaksana. Karyawan merupakan asset perusahaan, sehingga perlu dipertahankan agar mau bekerja dengan baik. Untuk mempertahankan karyawan dapat menggunakan media tunjangan atau bisa juga disebut program kesejahteraan karyawan untuk meningkatkan motivasi kerja karyawan agar dapat bekerja dengan baik.

Dalam mengelola karyawan agar tetap produktif memang tidak mudah karena karyawan memiliki keinginan yang berbeda-beda, oleh karena itu perusahaan memerlukan suatu program yang dapat memberikan kepuasan karyawan sehingga perusahaan dapat mempertahankan karyawan yang berpotensi, loyal, dan berdedikasi tinggi dalam bekerja. Karyawan yang demikian itu dapat menunjang keberhasilan perusahaan dalam menjalankan aktivitasnya..

\section{Metode Penelitian/Method}

Untuk penelitian ini populasi berjumlah 45 (empat puluh lima) orang. Populasi diambil dari seluruh pegawai PT. PLN (persero) pembangkitan Pandan. Seluruh populasi tersebut juga sekalian menjadi sampel dalam penelitian ini. Teknik pengumpulan data Studi lapangan, yaitu dengan cara mengumpulkan data langsung dari lokasi penelitian yang dilakukan dengan cara menyebarkan koesioner.

\section{Uji Coba Instrumen Data}

Data penelitian tidak akan berguna jika instrument yang di pakai mengumpulkan data penelitian tidak reliability (tingkat andal) dan validity (tingkat absah) yang tinggi, maka untuk itu dilakukan Uji Reabilitas dan Uji Validitas data.

\section{Uji Reabilitas}

"Validitas adalah suatu ukuran yang menunjukan tingkat keandalan atau keahlian suatu alat ukur” (Riduwan, 2004 - 109). Untuk menguji validitas ada beberapa langkah sebagai berikut :

a. Menentukan nilai $r$ tabel :Dari tabel $r$, untuk df = n-2 dengan tingkat signifikan 5\%

b. Mencari nilai $r$ hasil. Dengan menggunakan aplikasi software SPSS 19 IBM

c. Mengambil keputusan. Jika $r_{\text {hasil }}$ positif, serta $r_{\text {hasil }}>r_{\text {tabel }}$ maka dinyatakan valid. Jika $r_{\text {hasil }}$ tidak positif, serta $r_{\text {hasil }}<r_{\text {tabel }}$ maka dinyatakan tidak valid

\section{Uji Validitas}

Pengujian reliabilitas dilakukan untuk mengetahui konsisten hasil sebuah jawaban tentang tanggapan responden. Pengukurn reliabilitas dalam penelitian ini dilakukan cara "One Shot atau pengukuran sekali saja dilakukan dengan cara hanya sekali saja kuesioner diberikan kepada responden dan kemudian hasilnya dibandingkan dengan pertanyaan lain atau mengukur korelasi antara jawaban" (Ghozali, 2005 :352). Selanjutnya Ghozali (2005:352) menyatakan bahwa : "Suatu Konstruk atau variable dikatakan reliable jika nilai Cronbach Alpha $>0,60$ "

\section{Uji Analisis Data}

Sedangkan uji analisis data yang digunakan adalah :

\section{Uji Koefisien Korelasi}

Untuk membuktikan adanya korelasi dinyatakankan dengan koefisien korelasi yang dihitung menggunakan rumus koefisien korelasi Karl Pearson product moment Sugiyono (2012:248). 
Penelitian akan memprediksi bagaimana pengaruh variabel independen terhadap dependen.untuk membuktikan adanya korelasi dinyatakan dengan koefisen korelasi yang dihitung dengan menggunkan rumus product moment, yaitu :

$$
r_{x y}=\frac{n \sum X Y-\left(\sum X\right)\left(\sum Y\right)}{\left\lfloor n \sum X^{2}-\left(\sum X\right)^{2}\right\rfloor\left\lfloor n \sum Y^{2}-\left(\sum Y\right)^{2}\right\rfloor}
$$

Besar kecilnya Koefisien Korelasi itu terletak antara +1 dan -1 . Jika hasil perhitungan positif berarti korelasi variabel yang satu dengan yang lainnya kuat. Untuk mengetahui tinggi rendahnya koefisien korelasi digunakan interprestasi angka menurut Sugiyono (2012:250) sebagai berikut :

$$
\begin{aligned}
& 0,00 \mathrm{~s} / \mathrm{d} 0,19=\text { Korelasi sangat rendah } \\
& 0,20 \mathrm{~s} / \mathrm{d} 0,3=\text { Korelasi rendah } \\
& 0,40 \mathrm{~s} / \mathrm{d} 0,59=\text { Korelasi sedang } \\
& 0,60 \mathrm{~s} / \mathrm{d} 0,79=\text { Korelasi kuat } \\
& 0,80 \mathrm{~s} / \mathrm{d} 1,00=\text { Korelasi sangat kuat }
\end{aligned}
$$

\section{Uji Determinasi}

Uji koefisien Determinasi $\left(\mathrm{r}^{2}\right)$ digunakan untuk mengukur seberapa jauh kemampuan model dalam menerangkan variasi variabel dependen.Koefisien determinasi dapat naik atau turun apabila satu variabel independen ditambahkan ke dalam model. Berbeda dengan $r^{2}$ yang pasti akan meningkat setiap tambahan satu variabel independen, tidak peduli apakah variabel tersebut berpengaruh secara signifikan terhadap variabel dependen. Untuk mengetahui pengaruh Actuating terhadap Produktivitas kerja, dapat dilakukan dengan menggunakan rumus perhitungan determinasi $\left(\mathrm{r}^{2}\right)$ dengan rumus sebagai berikut $: \mathrm{KD}=\mathrm{r}^{2} \mathrm{X} 100 \%$

\section{Regresi Linier Sederhana}

Untuk mengetahui pengaruh yang signifikan antara variabel $\mathrm{X}$ dengan variabel Y digunakan syarat regresi linier dengan menggunakan rumus berikut

$\mathrm{Y}=\mathrm{a}+\mathrm{bx}$

Dimana :

$\mathrm{Y}=$ Variabel terikat

$\mathrm{X}=$ Variabel bebas

$\mathrm{a}=$ Intersep/konstanta

$\mathrm{b}=$ Koefisien regresi

Untuk memperoleh garis regresi sederhana diperlukan data dari variabel X (Actuating) dan variabel Y (Produktivitas Kerja), maka nilai a dan b dapat ditentukan dengan cara sebagai berikut :

$$
\begin{gathered}
\mathrm{a}=\frac{\sum Y-b \cdot \sum X}{n} \\
b=\frac{n \sum X Y-\left(\sum X\right)\left(\sum Y\right)}{n \sum X^{2}-\left(\sum X\right)^{2}}
\end{gathered}
$$

\section{Uji t-Statistik}

Setelah diketahui $r$ hitung maka dilakukan pengujian hipotesis. Menurut Suharsimi Arikunto (2006 : 294) rumus uji $t$ adalah sebagai berikut:

$$
t=\frac{r \sqrt{(n-2)}}{\sqrt{\left(1-r^{2}\right)}}
$$




$$
\mathrm{Df}=2
$$

Keterangan : $\mathrm{r}$ : Korelasi $\mathrm{X}$ dan $\mathrm{Y}$ yang ditemukan, $\mathrm{n}$ : Jumlah Sampel, $\mathrm{t}: \mathrm{t}$ Hitung yang selanjutnya dibandingkan dengan $\mathrm{t}$ Tabel. Dengan taraf signifikan $0.05 \mathrm{uji}$ dua arah dan $\mathrm{dk}=\mathrm{n}-$ 2, dengan ketentuan sebagai berikut :

a. Apabila nilai $\mathrm{t}$ hitung $>\mathrm{t}$ tabel, maka hipotesis alternative $(\mathrm{Ha})$ diterima dan hipotesis nol (Ho) ditolak.

b. Apabila nilai $t$ hitung < t tabel, maka hipotesis alternative (Ha) ditolak dan hipotesis nol (Ho) diterima

\section{Hasil}

\section{Hasil Uji Instrument Data}

\section{Uji Validitas}

Suatu kuesioner dikatakan valid jika setiap butir-butir pertanyaan pada suatu kuesioner mampu untuk mengungkapkan sesuatu yang akan diukur oleh kuesioner tersebut. Untuk menguji validitas, butir pertanyaan tersebut harus dibandingkan dengan $r_{\text {tabelpada }}$ tingkat signifikan 5\%. Dalam penelitian ini diketahui derajat kebebasan nya adalah $\mathrm{df}=45-2=43$, maka $r_{\text {tabel }}$ sebesar 0,2940.Adapun pengambilan keputusan untuk membuktikan valid atau tidaknya validitas instrument penelitian dengan criteria sebagai berikut:

a) Jika rhitung > rtabel, maka pertanyaan dinyatakan valid

b) Jika rhitung < rtabel, maka pertanyaan dinyatakan tidak valid

Dari hasil uji Validitas dengan menggunakan metode SPSS (Statistical PackagesFor The Social Scienses) versi 19 dapat diketahui bahwa data yang digunakan adalah data yang valid dan hal ini digambarkan sebagai berikut:

Tabel Hasil Uji Validitas Variabel X (Actuating)

Item-Total Statistics

\begin{tabular}{|c|c|c|c|}
\hline $\begin{array}{c}\text { Butir } \\
\text { pertanyaan }\end{array}$ & $\begin{array}{c}\text { Corrected Item- } \\
\text { Total Correlation }\end{array}$ & rtabel & Validitas \\
\hline Item 1 & 0,358 & 0,2940 & Valid \\
Item 2 & 0,590 & 0,2940 & Valid \\
Item 3 & 0,571 & 0,2940 & Valid \\
Item 4 & 0,633 & 0,2940 & Valid \\
Item 5 & 0,655 & 0,2940 & Valid \\
Item 6 & 0,734 & 0,2940 & Valid \\
Item 7 & 0,687 & 0,2940 & Valid \\
Item 8 & 0,750 & 0,2940 & Valid \\
Item 9 & 0,728 & 0,2940 & Valid \\
Item 10 & 0,560 & 0,2940 & Valid \\
\hline
\end{tabular}

Sumber : Data penelitian diolah 2017 dengan SPSS versi 19

Hasil Uji Validitas Variabel Y (Produktivitas Kerja) Item-Total Statistics

\begin{tabular}{|c|c|c|c|}
\hline $\begin{array}{c}\text { Butir } \\
\text { pertanyaan }\end{array}$ & $\begin{array}{c}\text { Corrected Item- } \\
\text { Total Correlation }\end{array}$ & rtabel & Validitas \\
\hline Item 1 & 0,446 & 0,2940 & Valid \\
Item 2 & 0,615 & 0,2940 & Valid \\
Item 3 & 0,590 & 0,2940 & Valid \\
Item 4 & 0,606 & 0,2940 & Valid \\
Item 5 & 0,701 & 0,2940 & Valid
\end{tabular}


eCo-Buss

\begin{tabular}{|c|c|c|c|} 
Item 6 & 0,720 & 0,2940 & Valid \\
Item 7 & 0,659 & 0,2940 & Valid \\
Item 8 & 0,690 & 0,2940 & Valid \\
Item 9 & 0,513 & 0,2940 & Valid \\
Item 10 & 0,402 & 0,2940 & Valid \\
\hline
\end{tabular}

Sumber : Data penelitian diolah 2017 dengan SPSS versi 19

Sesuai dengan tabel, dapat disimpulkan bahwa hasil uji validitas menunjukkan semua variabel pertanyaan valid karena rhitung> rtabel pada taraf signifikansi 5\%. Hal ini menjelaskan semua instrumen pertanyaan dari variabel X ( Actuating ) dan Variabel Y (Produktivitas Kerja ) teruji validitasnya.

\section{Uji Realibilitas}

Pengujian reliabilitas instrument dalam penelitian ini di analisis dengan teknik Cronbach Alpha. "Suatu konstruk atau variable dikatakan reliable jika nilai Cronbach Alpha>0,60"(Ghozali,2005:353).Hasil dari perhitungan reliabilitas dengan menggunakan aplikasi SPSS 19 dapat dilihat pada kolom Cronbach's Alpha item deleted dibawah ini:

Hasil Uji Reabilitas Variabel X (Actuating) Item-Total Statistics

\begin{tabular}{|r|c|c|c|}
\hline $\begin{array}{c}\text { Butir } \\
\text { Pertanyaan }\end{array}$ & $\begin{array}{c}\text { Cronbach's } \\
\text { Alpha if Item } \\
\text { Deleted }\end{array}$ & $\begin{array}{c}\text { Batas nilai } \\
\text { Reliabilitas }\end{array}$ & Keterangan \\
\hline Item 1 & 0,895 & 0,60 & Reliabil \\
Item 2 & 0,880 & 0,60 & Reliabil \\
Item 3 & 0,882 & 0,60 & Reliabil \\
Item 4 & 0,877 & 0,60 & Reliabil \\
Item 5 & 0,877 & 0,60 & Reliabil \\
Item 6 & 0,870 & 0,60 & Reliabil \\
Item 7 & 0,873 & 0,60 & Reliabil \\
Item 8 & 0,868 & 0,60 & Reliabil \\
Item 9 & 0,871 & 0,60 & Reliabil \\
Item 10 & 0,882 & 0,60 & Reliabil \\
\hline
\end{tabular}

Sumber : Data penelitian diolah 2017 dengan SPSS versi 19

Hasil Uji Reabilitas Variabel Y(Produktivitas Kerja) Item-Total Statistics

\begin{tabular}{|r|c|c|c|}
\hline $\begin{array}{c}\text { Butir } \\
\text { Pertanyaan }\end{array}$ & $\begin{array}{c}\text { Cronbach's } \\
\text { Alpha if Item } \\
\text { Deleted }\end{array}$ & $\begin{array}{c}\text { Batas nilai } \\
\text { Reliabilitas }\end{array}$ & Keterangan \\
\hline Item 1 & 0,872 & 0,60 & Reliabil \\
Item 2 & 0,860 & 0,60 & Reliabil \\
Item 3 & 0,862 & 0,60 & Reliabil \\
Item 4 & 0,862 & 0,60 & Reliabil \\
Item 5 & 0,853 & 0,60 & Reliabil \\
Item 6 & 0,852 & 0,60 & Reliabil \\
Item 7 & 0,857 & 0,60 & Reliabil \\
Item 8 & 0,854 & 0,60 & Reliabil \\
Item 9 & 0,868 & 0,60 & Reliabil \\
Item 10 & 0,876 & 0,60 & Reliabil \\
\hline
\end{tabular}




\section{Sumber : Data penelitian diolah 2017 dengan SPSS versi 19}

Berdasarkan output aplikasi SPSS 19 yang diolah, diperoleh nilai koefisien reliabilitas pada seluruh variabel penelitian lebih besar dari $0,60(>0,60)$ yang menunjukkan bahwa instrumen penelitian tepat. Maka instrumen variabel-variabel yang digunakan tersebut adalah reliabel dan dapat digunakan dalam penelitian.

\section{Uji Analisis Data}

\section{Uji Korelasi}

Dari perhitungan koefisien korelasi tersebut ,maka dapat diperoleh koefisien korelasi positif antara variable $\mathrm{X}$ dan $\mathrm{Y}$ adalah dengan nilai 0,683 artinya terdapat hubungan antara Actuating (variable $\mathrm{X}$ ) dengan Produktivitas kerja (variable $\mathrm{Y}$ ) dan hubungan tersebut tergolong korelasi kuat berkisar antara 0,60 s/d 0,79 = Korelasi kuat berarti ada hubungan yang kuat antara variabel $\mathrm{X}$ dan variabel Y menurut pendapat Sugiyono.

\section{Uji Koefisien Determinasi}

Maka dilakukan perhitungan dengan menggunakan rumus Product Moment agar data yang diperoleh lebih valid. $r^{2}=46,65 \%$. Dari perhitungan diatas diperoleh besarnya pengaruh variabel X (Actuating) terhadap variabel Y (Produktivitas kerja) adalah 46,65\% dan sisanya 53,35\% dipengaruhi oleh variabel lain seperti: Sarana dan Prasarana dan sebagainya.

\section{Uji Regresi Linear Sederhana}

Hasil Uji analisis regresi linear sederhana diperoleh persamaaan $Y=14,036+0,664 X$ yang menyatakan bahwa hubungan antara Actuating (variabel X) terhadap Produktivitas kerja (variabel Y) adalah hubungan kearah positif, artinya apabila nilai X (Actuating) $=0$ maka nilai $\mathrm{Y}$ (Produktivitas Kerja) $=14,036$ dan apabila nilai $\mathrm{X}=1$, maka nilai $\mathrm{Y}$ bertambah menjadi 14,7.hal ini berlaku jika diasumsikan variable lain dalam penelitian ini konstan.

\section{Uji Hipotesis (uji t)}

Dari hasil perhitungan tersebut, maka diketahui nilai t-hitung sebesar 6,138 sesuai dengan kaidah yang berlaku, bahwa apabila nilai t hitung lebih besar dari nilai t tabel, maka hipotesis alternatif (Ha) diterima dan Hipotesa nol (H0) ditolak. Dari kasus ini nilai t hitung 6,138 lebih besar dari nilai t tabel yaitu sebesar 2,017maka hipotesis yang diajukan penulis yaitu: Actuating menyokong Produktivitas kerja PT.PLN (Persero) Pembangkitan Sumatera bagian Utara Sektor Pembangkitan Pandan diterima

\section{Simpulan}

Berdasarkan penjelasan-penjelasan pada uraian sebelumnya, penulis mencoba menarik kesimpulan dan memberikan saran yang dianggap penting sebagai bahan masukan didalam peningkatan Produktivitas kerja karyawan pada PT.PLN (Persero) Pembangkitan Sumatera bagian Utara Sektor Pembangkitan Pandan.

Bahwa Actuating pada PT.PLN (Persero) Pembangkitan Sumatera bagian Utara Sektor Pembangkitan Pandan dapat dikatakan masih perlu diperbaiki dan ditingkatkan karena hal ini sangat berpengaruh kepada Produktivitas kerja karyawan pada kantor tersebut. Pimpinan PT.PLN (Persero) Pembangkitan Sumatera bagian Utara Sektor Pembangkitan Pandan harus lebi memperhatikan Actuating karyawan, sehingga dengan demikian akan meningkatnya Produktivitas kerja karyawan. Selanjutnya pimpinan selalu membangun komunikasi yang bersifat dua arah, untuk mengetahui dan mencari informasi tentang kinerja karyawan, sehingga dengan demikian akan diketahui loyalitas dari karyawan yang ada pada PT.PLN (Persero) Pembangkitan Sumatera bagian Utara Sektor Pembangkitan Pandan. Pimpinan juga harus dapat melakukan kerja 
sama dalam pengambilan keputusan, dengan karyawan sehingga dengan demikian akan muncul rasa kebersamaan dan rasa memiliki dari karyawan itu sendiri.

\section{Daftar Pustaka}

Arikunto, Suharsimi (2009), Manajemen Penelitian, Jakarta: Rineka Cipta.

Barata, Atep (2004), Dasar-dasar Pelayanan Prima, Jakarta : Elex Media. Komputindo.

Chrisyanti, Irra (2011), Manajemen Perkantoran, Jakarta, PT. Prestasi Pustakaraya.

Donni, Juni Priansa, S.P.d,SE,S.S,M.M,QWP, Drs. Agus Garnida, M.M (2013), Manajemen Perkantoran, Bandung: Alfabeta.

Haryadi, Hendy (2009), Administrasi Perkantoran untuk Manajer dan Staf, Jakarta Selatan : Visimedia.

Hardiyansyah (2011), Kualitas Pelayanan Publik Konsep, Dimensi, Indikator dan Implementasinya, Yogyakarta: Gava Media.

Istianto, Dr. Bambang (2009), Manajemen Pemerintahan Dalam Perspektif Pelayan Publik, Jakarata: Mitra wacana Media.

Kasmir, (2006), Manajemen Perbankan. Jakarta : PT. Raja Grafindo Persada.

Liverty, (2007), Administrasi Perkantoran Modern, Yogyakarta: The Liang Gie.

Mills, Geoffrey, et al, (1991), Manajemen Perkantoran Modern, Jakarta : Binarupa Aksara.

Nuraida, Ida (2008), Manajemen Administrasi Perkantoran, Yogyakarta : Kanisius.

Ratminto \& Atik Septi Winarsih (2006), Manajemen Pelayanan, Jakarta: Pustaka Pelajar.

Siagian, Sondang P. (2003), Filsafat Administrasi, Jakarta: PT. Bumi Aksara.

Sukoco, Munir Badri (2006), Manajemen Administrasi Perkantoran Modern, Jakarta : Penerbit Erlangga

STIE Al-Washliyah Sibolga/Tapanuli Tengah, 2015, Pedoman Penulisan Laporan Penelitian Penyusunan Skripsi. Sibolga 